\title{
Tooth as a Graft Material?
}

Keywords: alveolar bone preservation; bone grafting; graft; tissue engineering; tooth graft.

Regenerating alveolar bone remains an elusive goal and a challenge to the periodontist. The gold standard for alveolar bone repair is autogenous bone graft, though it is difficult to obtain adequate donor tissue. Increasing demand of graft material to augment alveolar bone led to different grafting materials from allograft, xenograft to alloplasts. There have been numerous studies on different techniques using regenerative materials over the years and the quest is still on.

The tooth, being autogeneous, has no risk of immune reaction and because of easy availability could be an ideal substitute for bone regeneration. The dentinal matrix obtained from the tooth has to be demineralized before its use as a graft material. The demineralized matrix is highly biocompatible and can support cell growth and proliferation. A nonfunctional or unsalvageable tooth can be obtained from the patient to be used as a donor for procurement of the graft material. The demineralized dentin matrix (DDM) which is organic material has shown to possess osteogenic potential. DDM have been actively tested in implant osseointegration and bone remodelling capacity, thus enhancing implant primary stability. Teeth, cartilages, nerves, and maxillofacial bones all share identical origin - the neural crest cells thus teeth and bones share many similarities. DDM can be a boon in regenerative periodontics due to its similarities to bone. ${ }^{1}$

Tooth derived bone substitutes find a lot of clinical applications. It was first reported in Korea by Kim et el by using as autogenous tooth derived bone graft along with guided tissue regeneration at the time of implant placement. Histomorphometric analysis of the samples during healing period of 3 to 6 months showed new bone formation in 80 to $86 \%$ of the area of interest with excellent bone remodeling. ${ }^{2}$

Alveolar bone preservation is a commonly performed practice these days and DDM can be used in tooth socket preservation to preserve the residual alveolar bone immediately after tooth extraction. ${ }^{3}$ It can also be used for ridge augmentation to increase the dimensions of alveolar bone in cases of deficiencies and deformities. ${ }^{4}$

Pneumatization of maxillary sinus may sometimes complicate placement of implant. Lee et al showed a faster and superior quality of bone formation in sinus augmentation using DDM. ${ }^{5}$ Kim et al histologically proved new bone formation when subjected to Guided Bone Regeneration using DDM. ${ }^{6}$

Based on the potentials of osteoconduction, osteoinduction and osteogenesis through growth factors in tooth and similar histogenesis between tooth and bone, a novel bone graft material can be developed utilizing the inorganic and organic components of an extracted tooth.

In the country like Nepal where periodontal disease prevalence is high ${ }^{7}$ which leads to early tooth loss and a need for replacement, this type of graft can be invaluable because of the easy availability, low cost and absence of antigenicity. Tooth can be considered as a safe and effective bone graft material and can be a blessing in the regenerative world.

\section{Correspondence:}

Dr. Shaili Pradhan

Department of Dental Surgery,

National Academy of Medical Sciences, Kathmandu, Nepal. email: shaili_p@yahoo.com

\section{Citation}

Pradhan S. Tooth as a Graft Material?. J Nepal Soc Perio Oral Implantol. 2018;2(1):1

\section{REFERENCES}

1. Bhattacharjya C, Gadicherla S, Kamath AT, Smriti K, Pentapati KC. Tooth derived bone graft material. World J Dent. 2016 Jan$\operatorname{Mar} ; 7(1): 32-5$

2. Kim YK, Kim SG, Byeon JH, Lee HJ, Um IU, Lim SC, et al. Development of a novel bone grafting material using autogenous teeth. Oral Surg Oral Med Oral Pathol Oral Radiol Endod 2010 Apr;109(4):496-503.

3. Kim YK, Kim SG, Kim KW, Um IW. Extraction socket preservation and reconstruction using autogenous tooth bone graft: J Korean Assoc Maxillofac Plast Reconstr Surg. 2011;33:264-9.

4. Kim YK, Yi YJ. Horizontal ridge augmentation using ridge expansion and autogenous tooth bone graft: a case report. J Dent Rehabil Appl Sci. 2011;27:109-15.

5. Lee YJ, Kim YK, Kim GS and Lim CS. Histomorphometric study of sinus bone graft using various graft material. J Dent Rehabil Appl Sci. 2011;27:141-7.

6. Kim YK, Lee HJ, Kim KW, Kim SG, Um IW. Guided bone regeneration using autogenous teeth: case reports J Korean Assoc Maxillofac Surg. 2011;37:142-7.

7. Pradhan S, Bhat MK. Assessment of periodontal status of rural Nepalese population using the community periodontal index. J Nepal Dent Assoc. 2009;10(2):97-104. 